\title{
O passado como negócio: o tempo revolucionário (1930)
}

\section{The past as business: revolution time (1930)}

Noé Freire Sandes

No Diário de Getúlio Vargas, publicado em 1995, algo inquieta o leitor: as poucas referências ao ex-presidente Washington Luís, com quem privara de grande intimidade e de quem fora, inclusive, ministro da Fazenda. Em 20 de novembro de 1930, Vargas escreve:

Bem amargas deveriam ser as reflexões do dr. Washington Luís. Recordei-me que muito mais havia eu sofrido em torturas morais, pela quebra de amizades e compromissos resultantes da campanha da Aliança, e pelas perspectivas e ameaças que de futuro poderiam advir,

Noé Freire Sandes é professor associado II do Departamento de História da Universidade Federal de Goiás e bolsista de produtividade no CNPq (noefsandes@uol.com.br).

Artigo recebido em 22 de dezembro de 2008 e aprovado para publicação em 4 de março de 2009.

Nota do autor: Este artigo é resultado de pesquisa realizada com apoio do CNPq.

Estudos Históricos, Rio de Janeiro, vol. 23, n 43, janeiro-junho de 2009, p. 125-140. 
acarretando prejuízos e desgraças para o Rio Grande e para os que o acompanharam, e tudo ser atribuído a mim, como responsável. Quantas vezes desejei a morte como solução da vida. E, afinal, depois de humilhar-me e quase suplicar para que os outros nada sofressem, sentindo que tudo é inútil, decidi-me pela revolução (...). O sr. Washington Luís provocou a tormenta, e esta o abateu. Dizem que o destino é cego. Deve haver alguém que o guie pela mão. (Vargas, 1995: 27)

Essa amargura a que Vargas se refere, ao rememorar o destino de um presidente da República, era certamente compartilhada pelas duas lideranças políticas envolvidas, em lados opostos, no processo revolucionário de outubro de 1930.

Ao garimpar as esparsas menções a Washington Luís, percebo que elas denunciam o veto à lembrança e ao nome do ex-presidente. No primeiro volume, ele é confundido com Washington Pires, ministro da Educação no período de 1932 a 1934. Em outra passagem, o presidente comenta o boato, considerado absurdo, de que o governo do Rio Grande teria, às vésperas da revolução, enviado recursos para financiar o assassinato de Washington Luís. ${ }^{1} \mathrm{Um}$ outro aspecto corrobora essa falta de destaque: o nome do ex-presidente nem sequer consta do índice biográfico que acompanha a publicação dos dois grossos volumes.

Naquele 20 de novembro de 1930, que merecera uma página bem reflexiva no Diário de Getúlio Vargas, Washington Luís partira para seu longo exílio. Sobre ele recaía a culpa da Revolução de Outubro: seu pretenso autoritarismo conduzira a sucessão presidencial para caminhos imprevisíveis. Fica claro que a amargura é uma página avulsa marcada pelas emoções contidas diante da vitória eleitoral de Júlio Prestes, que provocara forte abatimento em Vargas. A decisão de humilhar-se, na tentativa de proteger os correligionários - descrita no trecho do Diário -, possivelmente se vincula ao momento em que tudo parecia perdido, e a justificativa para a quebra de acordos, como o de evitar a realização de comícios no Rio de Janeiro, certamente pesava sobre os ombros do chefe do governo revolucionário. Entretanto, a revolução redefiniu o rumo dos acontecimentos. Afinal, Washington Luís não foi abatido por uma tormenta que ele mesmo provocara? O castigo não tardou. No ambiente marcado por expectativas, o exílio do ex-presidente poderia representar um alívio para as torturas morais que, timidamente, foram registradas nas páginas do Diário de Vargas. Numa tentativa musical de registrar o clima do momento, numa mistura de marcha com embolada, Lamartine Babo compõe: "O Doutor Barbado foi-se embora, deu o fora/ Não volta mais/ Não volta mais".

O Doutor Barbado permaneceria no exílio por 15 longos anos, só retornando ao Brasil em 1946. Poderia ter voltado antes, com a anistia decretada em 
1934, mas preferiu manter-se na Europa. O que teria motivado tal decisão? Difícil ensaiar qualquer resposta conclusiva. Creio, porém, que a presença de Getúlio Vargas na presidência da República feria mortalmente os brios de Washington Luís. Favoravelmente a essa tese testemunha o fato de que, enquanto Getúlio esteve à frente do governo, o ex-presidente permaneceu no exterior. Não havia processo algum contra ele, mas o ex-presidente escolheu o exílio. Longe da sua terra, optou, talvez como penitência, pelo silêncio, recusando-se a comentar, publicamente, os acontecimentos políticos brasileiros. ${ }^{2}$ Washington Luís tinha suas suposições, que foram rapidamente confirmadas. A presença de Vargas no poder, após 1934, sinalizava a permanência do tempo da revolução.

\section{Memória da revolução}

As primeiras interpretações do movimento procuraram demarcar a atuação dos seus protagonistas. Numa obra publicada em 1931-Outubro-, prefaciada por Osvaldo Aranha, Virgílio Melo Franco organiza sua narrativa na perspectiva do vencedor. Após elaborar uma rápida síntese da história política republicana, o autor delineia um rico quadro dos conflitos que afastaram Minas Gerais de São Paulo, cujo resultado foi a formação da Aliança Liberal. Rememora então, em minúcias, a trama que conduziu os revolucionários à vitória. Ao fim da narrativa, Melo Franco aborda o caso de São Paulo: certo de que mais uma vez as relações entre os dois estados definiriam os rumos da República, registrou, portanto, que nada tinha a ver com o tratamento dispensado pelos revolucionários aos membros do Partido Democrático em São Paulo.

Anunciavam-se momentos tormentosos para os revolucionários, indicando a abertura de um período de incertezas. Na conclusão de seu livro, Melo Franco (1931: 469) exime-se da obrigação de explicar o sentido da revolução: "a revolução não foi boa nem má: - a revolução foi indispensável e como tal invencível". O revolucionário, diante da inutilidade dos julgamentos morais, apelou para o pragmatismo, mas a Primeira Grande Guerra, a Gripe Espanhola e a Revolução Russa demarcaram o desafio de sua geração: o de resistir às concepções coletivistas alheias à formação mental dos brasileiros. Nas notas à quarta edição, em julho de 1931, afirmou, com certo amargor, que seu livro tinha provocado uma verdadeira tempestade: "Alguém já disse que as revoluções são como a química que destrói os próprios resíduos" (Melo Franco, 1931: 474).

Em Segunda República, publicado em 1931, Maurício de Lacerda busca igualmente, em seu testemunho, salientar sua participação no processo revolucionário e o descaminho da revolução: as violências contra funcionários públi- 
cos, a luta pelo controle dos cargos e funções associados ao Estado e a censura à imprensa indicavam a falta de rumo da segunda República, abrindo como possibilidade a instauração de uma terceira. Iniciava-se, então, a luta pela convocação da Constituinte.

Certamente, essas duas narrativas - a de Melo Franco e a de Lacerda ocupam uma posição de destaque na formação da memória da revolução, pois eram testemunhos de atores diretamente envolvidos no processo político. Afloradas as subjetividades, percebia-se a insegurança reinante no novo regime. Alguns testemunhos lançaram-se ao campo da especulação política, como é o caso de Maurício Medeiros, que, em Outras revoluçães virão, publicado em 1932, identificou a permanência do presidencialismo como o combustível necessário para novas revoluções.

Em $A$ República que a revolução destruiu, de 1932, Sertório de Castro montou uma síntese da vida política da primeira República, reconstituindo, em traços largos, a queda de Washington Luís. No registro das impressões, destaca o desassombro do presidente deposto ao enfrentar o seu destino; em contrapartida, retrata o comportamento insidioso do líder revolucionário Getúlio Vargas. Iniciava-se assim, precocemente, o julgamento dos atores envolvidos no processo revolucionário, e a memória da revolução, entranhada nas rusgas e conflitos políticos, enfrentava a premente tarefa de explicar o significado de 1930.

Para os vitoriosos, o controle sobre a avaliação do passado era uma estratégia para atenuar a impetuosidade da crise política, recorrendo ao conhecido recurso de demonizar o passado recente; a primeira República logo foi batizada de velha, e sua experiência política deveria ser vetada como fonte de orientação para o presente. Os derrotados receberam a alcunha de "carcomidos" ou "decaídos", e suas vozes, se percebidas, deveriam assemelhar-se a lamúrias.

A partir do final de 1932, a tarefa de explicar o passado se defrontava com outras expectativas que anteviam um quadro de estabilidade, apesar da continuidade das disputas políticas. Com o fim da revolução paulista e a convocação da Constituinte, era possível divisar as possibilidades abertas no curso do processo revolucionário. Nessa direção, as interpretações de Barbosa Lima Sobrinho e de Virgínio Santa Rosa, ambas publicadas em 1933, merecem destaque. Ciente de que, em regra, as paixões dominam as interpretações do presente, Barbosa Lima Sobrinho (1975: XV) inverte o postulado tradicional:

Costuma-se dizer que a história deveria ser escrita pela posteridade, uma vez que os contemporâneos não saberiam fugir a prevenções e interesses pessoais. Entretanto, precisamos não esquecer que, frequentemente, a posteridade acomoda a narrativa de sucessos passa- 
dos, aos sentimentos, ou paixões, das épocas em que se acham situados os historiadores.

$\mathrm{O}$ jornalista anuncia um compromisso com a verdade e a justiça e se apoia não só em jornais e documentos da época, mas também em informações confidenciais. Não menosprezou, porém, sua opinião, pois, graças às suas funções no fornal do Brasil, conhecia de perto os sucessos e os atores envolvidos. Barbosa Lima Sobrinho se aproxima das experiências vividas em 1930 e insiste em advertir sobre os riscos que espreitavam o presente. Previa também um horizonte político de sombras, que demarcavam a distância entre o projeto liberal e a prática política do governo provisório. Apesar da grande quantidade de obras divulgadas a respeito da revolução vitoriosa, seu livro esgotou-se em poucos meses, mesmo com uma tiragem - expressiva para época - de quatro mil exemplares. Ainda no prefácio, Barbosa Lima registra o elogio de Borges de Medeiros a sua interpretação sobre o processo revolucionário, o que o leva a afirmar:

Limitei-me a considerar a classificação como aprovação da fidelidade da minha narrativa e da interpretação que apresentava. Mesmo Getúlio Vargas e Osvaldo Aranha não tinham dúvida em averbar o meu estudo como obra séria, liberta de estreitos facciosismos, embora discordando de algumas interpretações apresentadas (Barbosa Lima Sobrinho, 1975: XI).

O jornalista desconhecia a recepção que seu livro tivera por parte de Getúlio Vargas. O sucesso da interpretação e seu pessimismo em relação aos rumos da revolução levaram o presidente a classificá-lo como um texto de oposição, conforme registra em seu Diário, entre os dias 13 e 14 de outubro de 1933: "Disse-me [Oswaldo Aranha] que o livro de Barbosa Lima atacando-me foi inspirado em João Neves" (1995: 243).

Ao enfocar, em uma de suas crônicas, as peculiaridades da busca pela verdade empreendida por Barbosa Lima Sobrinho, o jornalista Costa Rego comenta:

Na realidade, ele haver-se-á, talvez, enganado; mas não mentiu. Não mentiu, no sentido de que tivesse dosado suas narrativas de uma paixão apriorística, nem a favor dos acontecimentos e de seus homens, nem contra eles. A bem dizer, Barbosa Lima Sobrinho não descobriu a verdade; apenas a rememorou. Todo o mérito de seu trabalho está 
na minúcia com que aviva os fatos, apagados no curso do tempo. (Correio da Manhã, 14/10/1933, p. 2)

O comentário de Costa Rego legitima a interpretação daqueles que viveram a revolução e reconheceram a capacidade do jornalista em confrontar, pela rememoração, o apagamento das diferentes interpretações do movimento de outubro: "O livro de Barbosa Lima Sobrinho põe, dir-se-ia, os acontecimentos em câmara lenta, detendo-nos a atenção em cada minúcia esquecida, desfazendo em uma palavra a formidável ilusão de ótica de todo o extenso filme revolucionário" (Correio da Manhã, 14/10/1933, p. 2).

A alusão ao tempo lento da memória, em busca da diversidade do sentido do presente, se contrapõe à imagem da revolução como um filme extenso, mas, certamente, editado nas malhas de um poder que organiza as possibilidades de ordenação do passado como história.

Virgínio Santa Rosa publicou sua interpretação sobre o movimento revolucionário em 1933, concorrendo com Barbosa Lima Sobrinho na disputa pela compreensão do passado. $O$ sentido do tenentismo ganhou notoriedade na época, segundo informa Afonso Arinos de Melo Franco (1961: 323). O livro de Santa Rosa era francamente favorável à obra revolucionária, numa época em que os críticos ao governo provisório eram tachados de reacionários. No prefácio, o seu ensaio sobre o tenentismo é classificado como um gesto de audácia, diante da necessária distância para "avaliar serenamente os fatores em jogo", mas encontra um sentido comparativo que lhe permite assegurar que "o fenômeno que se está processando no Brasil é tão geral, já foi observado em tantos países, que pode ser diagnosticado com absoluta precisão" (Santa Rosa, 1976: XII). Nessa perspectiva, identifica nas revoluções burguesas o sentido geral que explica o processo político que se desenrolava no Brasil. Dizendo-se portador de uma lógica universal e isento de paixões, de modo a assegurar ao leitor a veracidade do seu ensaio, Santa Rosa (1976 : XII) acrescenta:

É preciso também despir os antolhos do fetichismo democrático e abandonar o vício sentimental, genuinamente nacional, de qualificar um movimento político-social pela honestidade e correção moral das personalidades que o dirigem. Isso é muito pouco e impede a verdadeira compreensão do sentido dos acontecimentos.

Entre Barbosa Lima Sobrinho e Virgínio Santa Rosa há notáveis diferenças. Enquanto o primeiro pretende atingir a verdade, analisando, além da documentação e da literatura, sua perspectiva de observador, bem como o seu aces- 
so aos principais personagens envolvidos na revolução, o segundo requer a distância das paixões, atribuindo sua "serenidade" ao fato de acompanhar o movimento longe dos centros de efervescência. É por essa via que Santa Rosa defende a veracidade de sua análise. Barbosa Lima Sobrinho avalia a revolução com algum pessimismo ao identificar a expressão regionalista do processo revolucionário e o oportunismo calculado do seu condutor, Getúlio Vargas. Santa Rosa apontava outras ameaças, entre as quais o recrudescimento do espírito de rebeldia das massas, caso a Constituinte não encaminhasse as reformas necessárias, em especial a agrária.

A tradução do tempo vivido pelos derrotados em 1930 acabou se perdendo na ausência de ouvidos e vozes capazes de garantir a permanência dessa interpretação na memória histórica. Em contraposição a esse silêncio, o tempo da revolução carregava consigo uma novidade: a promessa de ruptura com o passado apequenado. Explicar o significado da Revolução de 1930 representou, até certo ponto, o desejo de conduzir o projeto político de reordenação da experiência política brasileira. Entre 1930 e 1937 havia um claro sentido de continuidade entre o governo Vargas e as práticas políticas precedentes. O liberalismo, com algumas adaptações, apresentava-se como projeto político capaz de restabelecer a ordem social e econômica que fora malbaratada no governo Vargas.

A implantação do Estado Novo redefiniu a interpretação do passado, fundando um regime de historicidade ${ }^{3}$ que valorizava o passado colonial em detrimento da experiência republicana (Gomes, 1996). Em 1945, a deposição de Vargas parecia indicar o fim da experiência autoritária fundada no culto à pessoa do presidente. Entretanto, as urnas da eleição de 2 de dezembro guardavam surpresas: Getúlio Vargas se elegeu senador pelos estados do Rio Grande do Sul e de São Paulo, e o general Eurico Gaspar Dutra, ex-ministro de Vargas, derrotou o brigadeiro Eduardo Gomes - homem-símbolo da luta contra o regime fascista - e tornou-se presidente da República. O desenlace das eleições indicava que o passado varguista ganhara consistência diversa: o pretenso ditador havia descolado sua imagem da experiência da ditadura.

Há, sem dúvida, distintas representações do passado ao longo dos 15 anos em que Getúlio Vargas ocupou a presidência da República. Nessa constatação, interessa-me a lenta negociação entre passado e presente que resultou na formulação de uma cultura histórica.

\section{Da memória à história: o trânsito da interpretação}

O memorável é o resultado de um deslocamento: a lembrança capturada pelas malhas do presente formula uma nova representação do vivido. A memória 
torna-se fonte para o historiador que se interessa em explicar, sobretudo, a mudança. No tumultuado trânsito entre memória e história, certas interpretações são fundamentais para dar sentido ao passado; outras, ao perderem seu nexo com o presente, tornam-se secundárias. A ordenação do pensamento histórico atende aos imperativos do presente, a despeito do que sentiam e pensavam os homens que viveram o acontecimento.

Há, portanto, o registro do passado que se mantém vivo por meio de duas formas: pela memória social e pela historiografia - a primeira, marcada pela sua coerência interna, e a segunda pelo controle metódico. Uma de dentro, ancorada na vivência; a outra de fora, sugerindo controle e distância. Essa diferença conserva sentido didático na reflexão metodológica sobre a relação entre memória e história, mas a diferença se dilui quando se trata da constituição da cultura histórica. A história, como exercício disciplinar, impõe-se como produtora de um sentido por meio da interpretação das distintas leituras do passado que formam a cultura da lembrança (Guimarães, 2003).

Devo declarar aqui meu interesse em, sobretudo, realçar o sentido político da operação intelectual que, ao pressentir a subjetividade dos escritos do presente, propõe um veto à capacidade compreensiva do evento pelos contemporâneos. As crônicas, por exemplo, carregam o peso das disputas políticas de um passado inconcluso, enquanto a história é composta por narrativas produzidas depois de encerrado o período em foco (Falcon, 2007). O que está em jogo é a disputa pela interpretação do passado. Retomar a perspectiva dos contemporâneos não significa eliminar as diferenças entre as duas formas de representação do passado, entretanto é preciso reconhecer que a tensão resultante da comparação constitui um rico campo de estudos para o historiador interessado na cultura da lembrança. A reflexão sobre a formação da cultura histórica restabelece o nexo entre as interpretações e o agir humano, exigindo a retomada do diálogo com as razões políticas enredadas na formação de uma consciência histórica que visa ao saber legítimo (Rüsen, 2007).

Entre as décadas de 1940 e 1960, as interpretações sobre a Revolução de 1930 ainda estavam cercadas pelos relatos memorialísticos. ${ }^{4}$ José Maria Belo e Hélio Silva foram pioneiros na montagem de sínteses sobre a história republicana. Carlos Lacerda divulgava, no jornal Tribuna da Imprensa, o trabalho investigativo do historiador Hélio Silva, certo de que sua pesquisa guardava especial interesse para o público ainda marcado pelo trágico suicídio do presidente Getúlio Vargas. ${ }^{5}$ Por sua vez, Edgar Carone especializou-se na recolha da documentação, organizando um vasto panorama da nossa história política.

Em 1963, veio a lume uma nova edição do Sentido do tenentismo, para atender à imperiosa tarefa de refletir sobre o papel dos militares na sociedade brasileira. O livro foi publicado na coleção Cadernos do Povo Brasileiro, cujo es- 
copo era o de difundir as teses do pensamento nacionalista produzidas no Instituto Superior de Estudos Brasileiros (ISEB). ${ }^{6}$ Álvaro Vieira Pinto, um dos diretores da coleção, afirmou que sua "impressionante atualidade" justificava a reedição. No prefácio, Werneck Sodré ressalta a raridade da análise de Santa Rosa, que havia produzido uma interpretação exata dos acontecimentos na sua imediata sequência. Adverte que "a famigerada e inócua perspectiva histórica, ligada à conceituação de que a história só se ocupa do passado" advém do fato de que no Brasil as ciências sociais não se constituíram em campo autônomo. A exatidão da análise de Virgínio Santa Rosa pode ser percebida, ainda segundo Sodré, na identificação de interesses entre o tenentismo e a burguesia brasileira na luta contra o poder da classe latifundiária. A singular perspectiva sociológica de Santa Rosa se destacava do conjunto de obras ainda prisioneiras do tumulto dos acontecimentos e da ação das individualidades no processo revolucionário de 1930. Sodré faz, entretanto, uma constatação: o livro não despertou o interesse público, a despeito de os especialistas terem reconhecido seu mérito (Borges: 1992).

Na década de 1970, a transição democrática recoloca em pauta a discussão sobre a Revolução de 1930. Barbosa Lima Sobrinho publica, em 1975, a segunda edição do seu $A$ verdade sobre a Revolução de Outubro, alterando o seu posicionamento acerca do significado de 1930. Registra sua hesitação em autorizar a reimpressão da obra, pois sentia a necessidade de completá-la seguindo a "evolução do nacionalismo de Getúlio Vargas, culminando com a criação da Petrobrás e a profissão de fé da carta-testamento" (Barbosa Lima Sobrinho, 1975: XII). O tempo já era outro: o jornalista ocupara importantes posições no governo Vargas nos anos do Estado Novo e a defesa do nacionalismo refizera sua visão do passado. A reimpressão do seu livro se vinculava ao compromisso com o testemunho de um tempo específico e assim deveria ser entendido. A reavaliação do sentido da revolução exigira um novo esforço interpretativo:

Mas se não escrevi esse outro livro, tudo o que venho publicando e defendendo, ao longo desse período, integra-se nesse esforço de interpretação e de julgamento, em que este volume será um capítulo inicial, pois que a Revolução de 1930 deve enquadrar-se entre parâmetros marcados pela lei de dois terços e a criação da Petrobrás. (Barbosa Lima Sobrinho, 1975: XII)

Há um rico diálogo entre os dois prefácios: no de 1933, o autor duvida da isenção dos historiadores do futuro; no de 1975, reelabora o sentido do seu próprio testemunho, ao apelar para o desdobramento do tempo. Distante do campo 
de disputas políticas, Barbosa Lima Sobrinho redefiniu os nexos entre o passado e o presente. A atualização da lembrança alterou a compreensão do passado, razão pela qual sua análise da Revolução de 1930 permaneceria verdadeira se tomada como testemunho, mas deveria ser entendida como capítulo inicial de uma história cujo sentido completo só seria percebido posteriormente.

O sentido histórico é, portanto, distinto da memória comprometida com o presente imediato. Fica clara a exigência de outro patamar de observação: o abandono do tempo breve do testemunho em prol de um olhar que abarca o sentido final das mudanças. $\mathrm{O}$ memorialista reafirma a verdade do seu testemunho, mas desloca sua compreensão para outro tempo. Houve, enfim, uma visível sinalização do trânsito do julgamento do passado e, com isso, o olhar distante da história permitiu ao memorialista rever o sentido do seu testemunho, para adaptá-lo a uma nova consciência histórica.

A cuidadosa rede de proteção que foi armada, em 1933, para assegurar ao leitor a verdade do testemunho não resistiu à passagem do tempo. As indicações do segundo prefácio foram quase despercebidas pelo público e pelos especialistas. Em 1980, quando se comemoravam os 50 anos da Revolução de 1930 (Gadelha, 1984), Barbosa Lima Sobrinho rememorou, na Câmara dos Deputados, o evento. Sua presença se justificava, mais uma vez, pelo livro publicado em 1933. Na ocasião, referiu-se ao seu trabalho como uma "obra verdadeiramente de jornalismo", pois à observação direta do acontecimento ele acrescentara tudo que tinha sido publicado até aquela ocasião (Gadelha, 1984: 56). A percepção do livro como obra jornalística indicava uma saída para o impasse: a força testemunhal destacada em 1933 seguia os rastros de um tempo curto, próprio ao ofício do jornalismo.

Não deixa de ser curioso o esforço de Barbosa Lima Sobrinho para demarcar as pistas orientadoras da leitura do seu testemunho, decorridos quase 50 anos de sua primeira edição. O livro manteve-se como clássico, talvez por conservar o tom de denúncia e por distanciar-se de uma memória instrumental produzida pelo Estado, a despeito do esforço do autor em retificar seu julgamento acerca da revolução.

Boris Fausto, autor de Revolução de 1930: história e historiografia, publicado em 1972, longe de qualquer compromisso com a memória da revolução, elaborou uma análise do movimento, com o objetivo central de criticar o dualismo como chave para a interpretação da realidade brasileira. $\mathrm{O}$ debate ganhou atualidade como alternativa interpretativa para os impasses políticos que atormentavam a sociedade brasileira, no período posterior ao golpe de 1964 . A seta apontava para o alvo: a estratégia nacionalista do Partido Comunista Brasileiro defendida por intelectuais nacionalistas, entre os quais se destacava Werneck Sodré. 
A ausência de uma historiografia sobre a revolução não impediu Boris Fausto de ordenar sua leitura a partir de questões precisas, que submetiam as análises tradicionais ao crivo da crítica histórica. $\mathrm{O}$ autor, de forma pioneira, avaliou a produção historiográfica sobre a Revolução de 1930, quando historiadores e sociólogos ensaiavam as primeiras interpretações daquele acontecimento (Pacheco, 1998). O desejo de contrapor-se ao dualismo explicita claramente o limite do seu trabalho: "Só indiretamente, e de modo insuficiente, se irradia como tentativa de compreensão de toda a primeira República" (Fausto, 2002: 8). Em 1997, quando o livro completava quase três décadas, Boris Fausto, no prefácio, retoma o debate sobre a Revolução de 1930, avaliando a produção acadêmica recente sobre o tema. Ao encerrar seu balanço crítico, dirige seu olhar para os escritos dos contemporâneos:

Um olhar arrogante poderia ironizar os programas de salvação nacional contidos naqueles escritos, esquecido que o olhar arrogante do presente rapidamente se converte em passado. Prefiro assinalar que aquela gente tinha a percepção de estar vivendo novos tempos e, para bem ou para mal, não estava enganada. (Fausto, 2002: 26)

Aquela gente partilhou dos projetos políticos do presente por meio das interpretações elaboradas no calor dos acontecimentos: Santa Rosa vislumbrava o novo tempo como sintoma de uma era revolucionária; Barbosa Lima Sobrinho, ao contrário, denunciava os elementos de continuidade e os riscos do autoritarismo. Delineavam-se, assim, as linhas de continuidade e de descontinuidade que marcaram a memória da revolução. Boris Fausto organiza outro patamar de reflexão como operação histórica. A percepção dos contemporâneos é deslocada para um quadro mais amplo, embora o historiador reconheça a existência de "certo grau de verdade" nas interpretações daqueles que vivenciaram o movimento revolucionário. Tanto historiadores como memorialistas registraram a percepção de um novo tempo, entretanto o problema residia na configuração do tempo que se formava nas estratégias definidoras da articulação entre presente e passado.

Na verdade, em 1933, Costa Rego percebia claramente e denunciava, em seus escritos no Correio da Manhã, o uso ideológico da representação do passado na formulação de um tempo pretensamente novo (Sandes, 2008). Isto significa, portanto, que o olhar dos contemporâneos revelava uma percepção bem mais aguçada do presente do que a sugerida pelo historiador. Certamente, o mesmo se pode afirmar do testemunho de Barbosa Lima Sobrinho e de Virgínio Santa Rosa. A memória acompanha o acontecimento no rastro do tempo, organizando uma primeira interpretação do acontecimento, cuja validade está inscrita na leitura dos pri- 
meiros vestígios que demarcavam um sentido para o presente imediato. $\mathrm{O}$ desdobramento das interpretações é obra do historiador, sendo o passado ordenado a partir de um mirante diverso, distante da vivência dos contemporâneos.

Os testemunhos de Barbosa Lima Sobrinho e de Santa Rosa são devedores da experiência paulista e do pacto político firmado na Constituição de 1934. O peso desses dois eventos produziu uma nova percepção do futuro, pois as forças dissolventes que emergiram em 1930 seriam domadas, e a política dos Estados prevaleceria, mesmo diante das ameaças do discurso antiliberal. A reinterpretação do movimento, elaborada por Barbosa Lima Sobrinho na reimpressão do seu livro em 1975, indica justamente o aprisionamento do sentido da revolução pelos acontecimentos posteriores. O passado já era outro: a herança varguista havia conquistado a hegemonia como memória histórica.

Boris Fausto trava outro diálogo com o passado, e sua descrença na capacidade de representação de interesses coletivos por parte do movimento tenentista só pode ser compreendida em face da emergência de outra realidade em que os anos de 1930, 1932 e 1934 representavam apenas sombras que embaralhavam a análise do presente, já tão afastado da experiência vivida há três decênios. Das sombras desse passado distante vislumbrava-se, entretanto, a imagem da Era Vargas como projeto político com envergadura suficiente para orientar o presente, apesar do abalo político do golpe de 1964.

Interpretar a revolução significa, portanto, confrontar o passado sob diferentes perspectivas e compreender o modo como se dá a negociação dessas diferenças, cujo resultado imprime ao acontecimento o sentido de "fato histórico". A interpretação do passado, como negócio, tem como moeda a objetivação da subjetividade. Em outras palavras, trata-se de aferir a relação entre lembrança e esquecimento na constituição de uma cultura histórica. Nessa perspectiva, a experiência política da primeira República foi relegada ao esquecimento, e o passado pré-1930 fez-se distante. Abafado o tímido reformismo do final do Império, o regime republicano abandonou as bandeiras do liberalismo progressista em prol de uma estabilidade fundada no domínio oligárquico.

Encerrada, mesmo que parcialmente, a negociação sobre o passado da Revolução de 1930, os brasileiros, livres do passado, poderiam ensaiar um novo olhar sobre o Brasil moderno, como fez Boris Fausto (1978: 426) ao concluir sua análise acerca da Revolução de 1930:

Em poucos anos, por razões distintas, para a velha burguesia cafeeira, para a nascente "inteligentsia" da classe média encastelada no aparelho de Estado, para os tenentes revolucionários convertidos em canhestros estadistas, o mundo brasileiro anterior a 1930 incorporou-se definitivamente a um longínquo passado. 
Com o fim da Velha República, abre-se outro tempo. O passado, portanto, é matéria que se dobra continuamente pela ação do presente, e nas suas dobras se percebem as distintas camadas de cores com que foi representado. Nesse movimento não se chega à cor original, mas percebe-se o manejo do artesão, para que as técnicas e a combinação de cores revelem, apesar dos desgastes, as tonalidades do tempo. O historiador dialoga com o passado como terra estrangeira (Lowenthal: 1998), enquanto o memorialista é aprisionado na intimidade de sua experiência. Ambos padecem de um dilema: o de habitar numa morada estranha com o risco de perder-se ou de confundir-se na intimidade da morada de onde não se sabe sair.

Notas

1. As duas passagens citadas no Diário se encontram no volume I, nas páginas 253 e 291. Outra breve referência ao nome de Washington Luís encontra-se na página 104, quando Vargas comenta uma entrevista do ex-presidente contestando uma afirmação do ministro da Fazenda.

2. No Arquivo do Estado de São Paulo encontra-se boa parte da correspondência de Washington Luís. A ausência de um caráter mais pessoal na correspondência denuncia certo cuidado com a memória do ex-presidente. Em momento algum encontrei uma avaliação pessoal do golpe tramado em 1930, nem queixas ou avaliações capazes de denunciar os sentimentos e os afetos tão presentes nos jogos da política.

3. Utilizo a noção de "regime de historicidade" como instrumento heurístico que pode esclarecer o modo como uma sociedade trata o seu passado.

4. Deve-se registrar a emergência das obras clássicas sobre a formação da sociedade brasileira após a Revolução de 1930. A reflexão sobre o passado colonial guardava relação direta com a interpretação do presente. Percebe-se, nas obras de Caio Prado Jr. e Sérgio Buarque de Holanda, a crítica ao pensamento conservador alimentado pelo que Sérgio Buarque denominou, em Raizes do Brasil, "mussolinismo indígena". Entretanto, essa perspectiva não orientou o pensamento histórico comprometido com a leitura do presente: era imperiosa a tarefa de compor uma síntese da história republicana, conforme se depreende da leitura de História da República, de José Maria Belo, editada em 1940. A cada edição, o autor procurava acrescentar os acontecimentos definidores do sentido da vida republicana. A última edição data de 1976 e abarca o período de 1889 a 1954. Hélio Silva, em Sangue na areia de Copacabana (1964), considera os entrevistados como amigos que franquearam ao autor seus testemunhos e arquivos e presta homenagem aos seus "pares", incluindo seus nomes nas 
páginas iniciais de cada um dos cinco volumes que compõem a série $O$ ciclo de Vargas.

5. Hélio Silva publicou no jornal Tribuna da Imprensa versões jornalísticas de suas pesquisas sobre a história contemporânea do Brasil, conforme registra no livro: 1926. A grande marcha (1965).

6. Os títulos da coleção Cadernos do Povo Brasileiro eram sempre

Referências bibliográficas

BARBOSA LIMA SOBRINHO, Alexandre José. 1983. A verdade sobre a Revolução de Outubro - 1930. São Paulo: Alfa-Omega.

BORGES, Vavy Pacheco, 1992. Tenentismo e revolução brasileira. São Paulo: Brasiliense.

BORGES, Vavy Pacheco. 1998. Anos trinta e política. História e historiografia. In: FREITAS, Marcos César. Historiografia brasileira em perspectiva. São Paulo: Contexto. p. $159-182$.

BELO, José Maria. 1969. História da República. São Paulo: Companhia Ed. Nacional.

CASTRO, Sertório. 1982. A república que a revolução destruiu. Brasília: EdUnB.

FALCON, Francisco. 2007. Historiografia republicana e história da historiografia. In: HOMEM, Amadeu C. et al. (org.). A república no Brasil e em Portugal (1889-1910). Portugal: Imprensa Universitária de Coimbra; Brasil: Edufu. p. 389-409. marcados por uma questão direta, cuja resposta demandava a junção entre teoria e prática: Quem é povo no Brasil? (Werneck Sodré), Quem dará o golpe no Brasil? (Wanderley Guilherme), Quem pode fazer a revolução no Brasil? (Bolívar Costa), O que é a revolução brasileira? (Franklin de Oliveira). Para seguir o mesmo padrão, o livro de Santa Rosa foi publicado com o título O que foi a Revolução de 1930?

FAUSTO, Boris. 1978. A crise dos anos vinte e a Revolução de 1930. HGCB, São Paulo, Difel, tomo III, vol. 2. 2002. A Revolução de 1930: historiografia e história. São Paulo: Companhia das Letras.

FRANCO, Virgílio de Melo. 1931. Outubro, 1930. Rio de Janeiro, Schmidt.

FRANCO, Afonso Arinos de Melo. 1979. A alma do tempo: memórias. Rio de Janeiro: José Olympio; Brasília: INL.

GADELHA, Marcondes (org.). 1984. Revolução de 1930: Anais da Semana Comemorativa da Revolução de 1930. Brasília: Câmara dos Deputados.

GOMES, Ângela de Castro. 1996. História e historiadores. Rio de Janeiro, FGV. 2007. Cultura política e cultura histórica no Estado Novo. In: ABREU, Marta et al. (org.) Cultura política e leituras do passado: historiografia e ensino de história. Rio de Janeiro: Civilização Brasileira.

GUIMARÃES, Manoel L. S. 2003. A cultura histórica oitocentista: a constituição de uma memória disciplinar. In: PESAVENTO, Sandra 
J. (org.). História cultural: experiências de pesquisa. Porto Alegre: EdUFRGS.

HALBWACHS, M. 1990. A memória coletiva. São Paulo: Vértice.

HARTOG, François. 2003. Régimes d'historicité: presentisme et expériences $d u$ temps. Paris: Seuil.

LACERDA, Maurício. 1931. Segunda República. Rio de Janeiro: Freitas Bastos.

LOWENTHAL, D. 1998. Como conhecemos o passado. Projeto História, São Paulo, vol. 17.

MASTROGREGORI, Mássimo. 2006. Historiografia e tradição das lembranças. In: MALERBA, Jurandir (org.). A história escrita: teoria e história da historiografia. São Paulo: Contexto.
RICOUER, Paul. 2007. A memória, a história, o esquecimento. Campinas, Unicamp.

RÜSEN, Jörn. 2007. História viva: teoria da história - formas e funções do conhecimento histórico. Brasília: EdUnB.

SANDES, Noé Freire. 2008. O jornalista Costa Rego e o tempo revolucionário (1930). Revista Brasileira de História, São Paulo, vol. 28, n. 55.

SANTA ROSA, Virgínio. 1976. O sentido do tenentismo. São Paulo: Alfa-Omega.

SILVA, Hélio. 1964. 1931: Sangue na areia de Copacabana. Rio de Janeiro: Civilização Brasileira.

SILVA, Hélio. 1965. 1926: A grande marcha. Rio de Janeiro: Civilização Brasileira.

VARGAS, Getúlio. 1995. Diário. São Paulo: Siciliano; Rio de Janeiro: FGV.

\title{
Resumo
}

A memória histórica é o resultado de uma lenta negociação em que as disputas políticas se apresentam como parte do processo de ordenação do passado. A memória e a história - em perspectivas diversas - elaboram narrativas capazes de conferir sentido às mudanças operadas no mundo social. $O$ presente trabalho avalia as interpretações sobre o processo revolucionário ocorrido em outubro de 1930, enfatizando as distinções reveladoras do tempo e do lugar dos intérpretes em seu compromisso de explicar o passado.

Palavras-chave: memória, história, Revolução de 1930

\begin{abstract}
Historical memory is the result of a slow negotiation in which political disputes take part in the process of ordering the past. Memory and history in several perspectives - elaborate narratives that provide meaning for the changes which occur in the social world. This paper analyzes the revolutionary process which took place in October 1930 in Brazil. As well, it focuses on the distinctions that express the time and place of those who are in charge of interpreting the past.
\end{abstract}

Key words: memory, history, Revolution of 1930 


\section{Résumé}

La mémoire historique est le résultat d'une lente négociation où les disputes politiques font partie du processus d'agencement du passé. La mémoire et l'histoire - sous des perspectives différentes - élaborent des narratives qui donnent du sens aux changements du monde social. Cet article évalue les interprétations du processus révolutionnaire qui a eu lieu en octobre 1930, en soulignant les distinctions révélatrices du temps et du lieu des interprètes dans leur compromis d'expliquer le passé.

Mots clés: mémoire, histoire, revolution 